\title{
ACIDENTES PROVOCADOS POR LAGARTAS URTICANTES EM PONTA GROSSA - PARANÁ
}

\section{ACCIDENTS CAUSED BY URTICATING CATERPILLARS IN PONTA GROSSA - PARANÁ}

\author{
Ana Carolina Pinto da Cruz ${ }^{1^{*}}$, Ivana de Freitas Barbola ${ }^{2}$ \\ ${ }^{1}$ Pontifícia Universidade Católica do Paraná, Escola de Medicina, Curitiba, Paraná, Brasil \\ ${ }^{2}$ Universidade Estadual de Ponta Grossa, Departamento de Biologia Geral, Ponta Grossa, \\ Paraná, Brasil \\ *Autor correspondente: Ana Carolina Pinto da Cruz, Pontifícia Universidade Católica do \\ Paraná - PUCPR, Escola de Medicina - Rua Imaculada Conceição, 1155, Prado Velho - CEP \\ 80215-901, Curitiba, Paraná, Brasil. a.carol.p.cruz@gmail.com
}

\section{RESUMO}

Estuda-se pouco, no Brasil, os acidentes com lepidópteros. No entanto, sabe-se que a quase totalidade dos acidentes brasileiros decorrem do contato com lagartas. Considerando-se o número de acidentes por erucismo em Ponta Grossa (PR), este estudo analisa seus aspectos epidemiológicos. Nos 255 registros de acidentes referentes ao período de 2007 a 2010, coletados junto à base de dados do Sistema de Informação de Agravos de Notificação (SINAN), e disponibilizados pela Divisão de Vigilância Epidemiológica e Controle de Doenças da Secretaria Municipal de Saúde, a faixa etária mais propensa aos acidentes é a de 7 a 29 anos, sendo os membros superiores os locais de contato mais atingidos. Na busca ativa por lagartas, identificou-se todas as quatro famílias de importância médica: Saturniidae, Megalopygidae, Arctiidae e Limacodidae e as plantas hospedeiras observadas pertencem a nove famílias botânicas diferentes, com destaque para Rosaceae e Platanaceae. Concluiu-se que a cidade de Ponta Grossa apresentou uma taxa de incidência acumulada de 84.09 casos por 100.000 habitantes, cerca de 10 vezes maior que a média nacional, sendo o bairro de Nova Rússia o local pontagrossense com maior risco de novos acidentes.

Palavras-chave: lepidópteros; acidentes; erucismo; epidemiologia.

\begin{abstract}
Accidents caused by lepidopterans are poorly studied in Brazil and in most of the cases they are caused by direct contact with caterpillars. Considering that in the region of Ponta Grossa (Paraná, Brazil) there are a considerable number of accidents causing erucism, this study aims to analyze epidemiological aspects of lepidopterans. During the years 2007 to 2010, were recorded 225 erucism accidents by the Division of Epidemiological Surveillance and Disease Control (Sinan). They were made available by the Municipal Health Secretary (Ponta Grossa, Paraná, Brazil), showing that the most prone age for accidents occur between 7 to 29 years old, with the upper limbs as the most affected contact sites. The collected specimens were identified as belonging to four families of lepidopterans: Saturniidae, Megalopygidae, Arctiidae and Limacodidae. Furthermore, the observed hosts belong to nine different families of plants, especially Rosaceae and Platanaceae. The city of Ponta Grossa showed a cumulative incidence of 84.09 cases per 100,000 inhabitants, about 10 times higher than the national average, and the neighborhood of Nova Rússia the one presenting the highest risk for new accidents.
\end{abstract}

Keywords: lepidopterans; accidents; erucism; epidemiology. 


\section{INTRODUÇ̃̃O}

Lepidoptera é uma das principais ordens de insetos, apresentando cerca de 160.000 espécies descritas (GULLAN; CRANSTON, 2007). Costa (1994) define lepidopterismo como o termo que designa o acidente provocado por formas aladas de adultos (mariposas), enquanto que o acidente causado pela forma larval (lagarta) denomina-se erucismo.

De acordo com Cardoso e Haddad Junior (2005), os acidentes causados por lepidópteros constituem assunto pouco abordado na literatura brasileira, embora sejam comuns e gerem quadros clínicos diversos. Dos acidentes registrados com estes insetos, a quase totalidade decorre do contato com lagartas. De acordo com Martins, Andrade e Paiva (2006), a maioria dos envenenamentos por contato com animais/plantas em crianças menores de 15 anos foram causados por lagartas $(29,1 \%)$, sendo mais ocorrentes do que abelhas $(25,9 \%)$ e aranhas $(22,8 \%)$.

Os lepidópteros de importância médica representam um pequeno número dentro da ordem, sendo que, segundo Moraes (2003), aproximadamente quatro famílias apresentam interesse médico no Brasil: Megalopygidae, Saturniidae, Arctiidae e Limacodidae. Esta última (Limacodidae) não é considerada pelo Ministério da Saúde (BRASIL, 2001). O Ministério da Saúde ainda enfatiza a dificuldade que há para o real dimensionamento destes acidentes, que de modo geral, são subnotificados.

Alguns trabalhos realizados procuram relacionar as plantas hospedeiras com algumas famílias de lepidópteros (BIEZANKO; RUFFINELLI; LINK, 1974). Da mesma forma, Specht, Corseuil e Formentini (2005a), fizeram essa relação entre as plantas hospedeiras com a família Limacodidae e com a subfamília Hemileucinae (Saturniidae) (SPECHT; CORSEUIL; FORMENTINI, 2005b).

A maioria dos acidentes com lagartas urticantes ocorre no verão e no início do outono, quando as larvas eclodem de seus ovos e iniciam seu desenvolvimento. Entre diversas plantas, as lagartas podem ser encontradas em goiabeiras (Psidium guajava), abacateiros (Persea americana), cajueiros (Anacardium occidentale), roseiras (Rosa spp.), cafeeiros (Coffea sp.), eucaliptos (Eucalyptus spp.), figueiras (Ficus spp.), bananeiras (Musa spp.), mamoeiros (Carica spp.), mandioqueiras (Manihot esculenta) e seringueiras
(Hevea brasiliensis) (CAMPOLINA; JANUÁRIO, 2006).

Entre os fatores que favorecem o contato dos seres humanos com esses organismos estão: a expansão das áreas urbanas, turismo, e outros (MAGGI; FAULHABER, 2015). Canter et al. (2011), complementa que a incidência maior de acidentes com estes insetos se deve ao desmatamento, queimadas, extermínio de predadores naturais, loteamentos sem planejamento prévio e sem avaliação do impacto ecológico que isto acarreta, obrigando a procura das espécies por outros ambientes para sobreviver.

Rubio (2001) identificou a presença de uma das lagartas mais importantes para a saúde pública, Lonomia obliqua Walker, 1855, em várias regiões do Estado do Paraná, mas com predominância nas mesorregiões centro-sul e sudoeste. Para a Secretaria Estadual da Saúde do Estado do Paraná, citada por Gouveia (2004), o primeiro registro da presença deste animal no Paraná se deu em 1989, no município de Nova Cantú, com a identificação da larva da mariposa do gênero Lonomia. Desde então, este lepidóptero já foi identificado em vários municípios das regiões oeste e centro-sul do Estado (GOUVEIA, 2004).

Registros de ocorrência de acidentes com lagartas urticantes, obtidos junto à Secretaria Estadual da Saúde do Estado do Paraná (2010), mostram que o número de casos na cidade de Ponta Grossa vem aumentando com o passar dos anos, sendo que nos anos de 2001 e 2002 houve duas notificações com a lagarta Lonomia sp, a qual pode gerar um quadro clínico grave.

Levando em conta a crescente incidência de acidentes por contato com lagartas urticantes em Ponta Grossa, o presente estudo tem por finalidade ampliar os conhecimentos acerca dos aspectos epidemiológicos do erucismo, a partir da: (1) realização de busca ativa de lagartas urticantes em diversas regiões da cidade; (2) identificação taxonômica dos exemplares coletados e (3) levantamento e interpretação dos dados epidemiológicos, com o objetivo de gerar informações para a elaboração de estratégias de controle e de prevenção.

\section{MATERIAL E MÉTODOS}

o município de Ponta Grossa localiza-se no Segundo Planalto Paranaense, considerada cidade polo de uma das regiões mais populosas do estado, os Campos Gerais do Paraná, com uma população de 
311.611 habitantes, dos quais mais de $97 \%$ são moradores da zona urbana. (IBGE, 2011).

Os registros de acidentes referentes ao período de 2007 a 2010 foram pesquisados junto à base de dados do Sistema de Informação de Agravos de Notificação (SINAN), do Ministério da Saúde, que contém os parâmetros necessários ao cálculo dos principais indicadores epidemiológicos. Os dados foram disponibilizados pela Divisão de Vigilância Epidemiológica e Controle de Doenças da Secretaria Municipal de Saúde, sendo armazenados na forma impressa e eletrônica.

Com o objetivo de inventariar a fauna de lepidópteros urticantes ocorrentes na área urbana de Ponta Grossa, foram realizadas coletas diurnas entre os meses de dezembro a março, que correspondem aos meses de verão (época em que estes insetos são mais abundantes e ativos). Os locais de busca foram determinados com base nas suas características: procurou-se espaços públicos arborizados e com grande fluxo de pessoas, o que representa maior potencial para ocorrência de acidentes. Sendo assim, foram escolhidas as cinco principais praças da cidade: (1) Praça Barão do Rio Branco, (2) Praça Barão de Guaraúna, (3) Praça Getúlio Vargas, (4) Praça Marechal Floriano Peixoto e (5) Parque Ambiental; o sexto local escolhido foi o Campus Uvaranas da Universidade Estadual de Ponta Grossa.

Os animais encontrados foram capturados com pinça de aço inoxidável e acondicionados em recipientes transparentes com tampa de rosca. Quando encontrados em árvores, os ramos delas (contendo flores e/ ou frutos) foram coletados para posterior identificação da espécie, junto ao Herbário da Universidade Estadual de Ponta Grossa (HUPG).

No laboratório, as lagartas amostradas foram triadas e conservadas em álcool 70\%. Com auxílio de bibliografia especializada, as lagartas foram identificadas ao menor nível taxonômico possível, geralmente de família ou gênero, através de chaves de identificação para larvas (COSTA; IDE; SIMONKA, 2006). Os exemplares capturados estão depositados na Coleção Entomológica dos Campos Gerais da UEPG (CECG).

Com o objetivo de investigar os riscos de novos acidentes para a população, foram calculados os coeficientes de incidência acumulada $\left(\mathrm{IC}=\left(\mathrm{n}^{\circ}\right.\right.$ casos $/$ população) $* 10^{\mathrm{n}}$ ) no período de 2007-2010 para cada bairro e também para toda a cidade. Quanto aos registros de acidentes, foram analisadas as variáveis: sexo e faixa etária das vítimas, distribuição sazonal, locais anatômicos de contato e a evolução clínica dos casos. Estes diferentes parâmetros foram comparados quanto à sua frequência através do teste Qui-quadrado $\left(X^{2}\right)$, utilizando o software livre BioEstat versão 5.0. Esta pesquisa foi aprovada pelo Comitê de Ética em Pesquisa da Universidade Estadual de Ponta Grossa (parecer $n^{\circ}$ 52/2011).

\section{RESULTADOS E DISCUSSÃO}

\section{- Aspectos epidemiológicos}

No período de janeiro de 2007 a dezembro de 2010, ocorreram 255 acidentes por lagartas urticantes nos 16 bairros da cidade de Ponta Grossa (PR), com uma taxa de incidência (IC) acumulada de 84,09 casos por 100.000 habitantes. Deste total, três registros apresentaram endereço incompleto, não sendo possível, identificar o bairro. Assim, eles não foram computados na análise.

Os dados indicam que houve diferença significativa no número de acidentes $\left(X^{2}=100,74 ; \mathrm{p}<0,0001\right)$ e na taxa de incidência $\left(X^{2}=281,44 ; \mathrm{p}<0,0001\right)$ entre os diversos bairros, sendo o maior número absoluto de casos observados em Uvaranas, com 44 notificações, enquanto que o bairro Nova Rússia apresentou o maior risco de ocorrência de novos acidentes em relação ao seu número de habitantes, com incidência de 167,89 casos por 100.000 habitantes (Tabela 1).

Pela Tabela 2, nota-se que em 2007 e 2008 a incidência de acidentes em Ponta Grossa manteve-se no mesmo patamar, tendo um crescimento gradual a partir de $2009\left(X^{2}=3,839 ; p=0,2794\right)$. Em todo o Brasil, no ano de 2008 foram notificados 3.968 acidentes por lagartas, com uma incidência de 2/100.000 habitantes, sendo que a região Sul foi a que registrou o maior valor - 8/100.000 habitantes; (BRASIL, 2009). Em 2010, foram 3.274 acidentes, com incidência nacional de 1,72 acidentes/ 100.000 habitantes (BRASIL, 2011). No Paraná, as taxas de incidência variaram de 8,05 a 13,63/100.000 habitantes no período 2007-2010. 
Tabela 1 - Número de acidentes e coeficiente de incidência acumulada (IC) de acidentes por lagartas urticantes por 1.000 e por 100.000 habitantes nos bairros para Ponta Grossa (PR), no período de 2007 a 2010.

\begin{tabular}{l|c|c|c}
\hline Bairros & $\mathrm{n}^{0}$ acidentes $^{1}$ & $\mathrm{n}^{0}$ habitantes & IC/100 mil \\
\hline Nova Rússia & 33 & 19.656 & 167,89 \\
\hline Olarias & 12 & 8.545 & 140,43 \\
\hline Jardim Carvalho & 29 & 22.393 & 129,50 \\
\hline Órfãs & 16 & 13.107 & 122,07 \\
\hline Estrela & 8 & 7.548 & 105,99 \\
\hline Uvaranas & 44 & 44.450 & 98,99 \\
\hline Oficinas & 19 & 20.414 & 93,07 \\
\hline Boa Vista & 18 & 24.968 & 72,09 \\
\hline Centro & 8 & 12.325 & 64,91 \\
\hline Contorno & 18 & 28.386 & 63,41 \\
\hline Chapada & 3 & 23.166 & 56,11 \\
\hline Piriquitos & 5 & 5.417 & 55,38 \\
\hline Ronda & 12 & 22.219 & 54,18 \\
\hline Neves & 7 & 16.639 & 54,03 \\
\hline Col. Dona Luiza & 7 & 24.779 & 28,25 \\
\hline Cará Cará & 3 & & \\
\hline Endereço incompleto & 255 & 303.233 & 84,09 \\
\hline Total & &
\end{tabular}

Fonte: ${ }^{~}$ Secretaria Municipal de Saúde - Vigilância Epidemiológica e Controle de Doenças - SINAN NET - 2007 a 2010.

${ }^{2}$ INSTITUTO BRASILEIRO DE GEOGRAFIA E ESTATÍSTICA - censo 2010. População residente, por situação do domicílio e sexo (Tabela 608). Disponível em: http://www.sidra.ibge.gov.br/bda/tabela/protabl.asp?c $=608 \& z=c d \& o=3 \& i=P$.

Tabela 2 - Número de acidentes e coeficiente de incidência (IC) acumulado dos acidentes por lagartas urticantes por 1.000 e por 100.000 habitantes do município de Ponta Grossa (PR) e em todo o estado do Paraná, no período de 2007 a 2010.

\begin{tabular}{c|c|c|c|c}
\hline Ano & \multicolumn{2}{|c|}{ Ponta Grossa } & \multicolumn{2}{c}{ Paraná } \\
\hline & $\mathrm{n}^{\mathrm{o}}$ acidentes & $\mathrm{IC} / 100.000$ & $\mathrm{n}^{\mathrm{o}}$ acidentes & $\mathrm{IC} / 100.000$ \\
\hline 2007 & 58 & 18,61 & 1147 & 10,98 \\
\hline 2008 & 58 & 18,61 & 1424 & 13,63 \\
\hline 2009 & 62 & 19,89 & 1105 & 10,57 \\
\hline 2010 & 77 & 24,71 & 841 & 8,05 \\
\hline Total & 255 & 81,83 & 4.517 & 43,24 \\
\hline
\end{tabular}

Fonte: Secretaria Municipal de Saúde - Vigilância Epidemiológica e Controle de Doenças - SINAN NET - 2007 a 2010.

Na comparação com os dados gerais, a cidade de Ponta Grossa apresentou incidência acumulada de 18,61 por 100 mil habitantes para os anos de 2007 e 2008, 19,89/100.000 habitantes para 2009 e $24,71 / 100.000$ habitantes para 2010, significativamente maiores $\left(X^{2}=1093,635 ; \mathrm{p}<0,0001\right)$ que os valores observados para o estado do Paraná e cerca de 10 vezes a média nacional.

Segundo Canter et al. (2011), o crescimento da população urbana, que traz consigo mais desmatamento, loteamentos sem planejamento prévio e sem avaliação do impacto que isso acarreta e o extermínio de predadores naturais são as principais causas do aumento do erucismo.

Dados obtidos junto à Divisão de Vigilância de Zoonoses e Intoxicações (DEVA/SVS) da Secretaria Estadual da Saúde do Paraná confirmam que o número de acidentes causados por lepidópteros vem aumentando a cada ano na cidade (Figura 1). 
Figura 1 - Acidentes por contato com lagartas urticantes no período de 2003 - 2010, registrados em Ponta Grossa, PR.

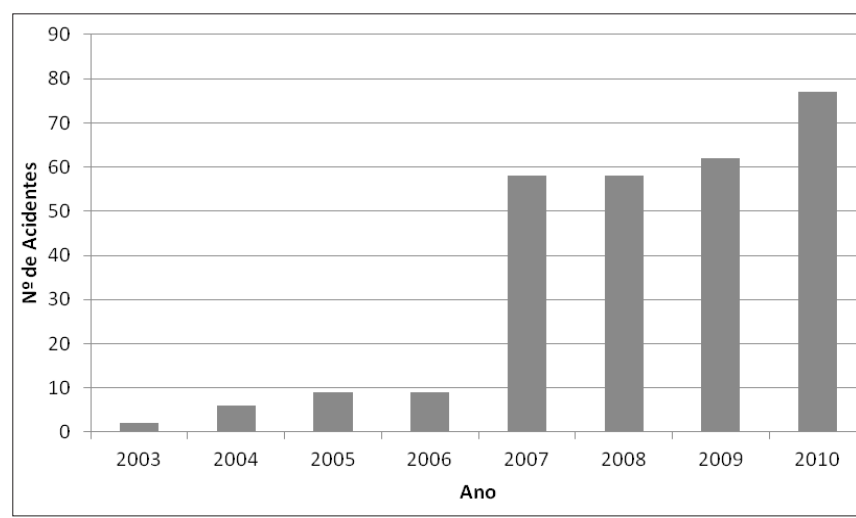

Fonte: Secretaria de Estado da Saúde do Paraná.

Os dados mostram uma evolução nos acidentes por contato com lagartas urticantes, que teve um incremento de aproximadamente 533\% entre 2006 e 2007. A hipótese é a de que essa elevação nos valores se deve ao aumento real do número de acidentes ou ainda, pode estar relacionado à melhora dos seus registros. Esta melhora deve-se a implantação do SINAN, o qual veio a atender a dificuldade encontrada no dimensionamento exato dos acidentes por lepidópteros que são, em geral, subnotificados (BRASIL, 2001). A subnotificação ocorre quando alguns casos não chegam ao conhecimento dos órgãos de saúde, por exemplo, quando o acidente não gera dores e/ou edemas. Assim, potenciais pacientes não são atendidos nas unidades de saúde, ficando esse acidente desconhecido.

Pelos registros analisados, observou-se que a maioria dos acidentes ocorreu na zona urbana (98\%), a maioria ocorreu em residências (92,5\%). Quanto aos acidentes relacionados ao trabalho, Ponta Grossa apresenta um índice extremamente baixo, correspondendo a apenas $1 \%$ dos registros. Tanto homens $(52,5 \%$ dos acidentes) quanto mulheres (47,5\%) estão sujeitos ao contato com as larvas de lepidópteros.

A Tabela 3, a qual apresenta a frequência por faixa etária, demonstra que a idade mais propensa aos acidentes está entre 7 e 29 anos $\left(X^{2}=80,96\right.$; p $<0,0001)$.
Tabela 3 - Frequência de acidentes por lagartas urticantes por faixa etária, no período de 2007 a 2010, para Ponta Grossa, PR.

\begin{tabular}{c|c|c}
\hline Faixa etária & Frequência & \% \\
\hline $0 \mid----7$ & 13 & 5 \\
\hline $7 \mid----18$ & 46 & 18 \\
\hline $18 \mid----29$ & 48 & 19 \\
\hline $29 \mid----40$ & 34 & 13 \\
\hline $40 \mid----51$ & 38 & 15 \\
\hline $51 \mid----62$ & 42 & 16 \\
\hline $62 \mid----73$ & 21 & 8 \\
\hline $73 \mid----84$ & 11 & 4 \\
$84 \mid----96$ & 2 & 1 \\
\hline Total & 255 & $100 \%$ \\
\hline
\end{tabular}

Fonte: Secretaria Municipal de Saúde - Vigilância Epidemiológica e Controle de Doenças - SINAN NET - 2007 a 2010.

Tais resultados divergem dos observados por Rubio (2001) em outro estudo realizado no estado do Paraná onde foi registrada maior frequência de acidentes por lagartas Lonomia entre crianças de zero a nove anos, seguida da faixa etária de 10 a 19 anos. Um levantamento realizado por Cardoso e Haddad Junior (2005) no Hospital Vital Brasil (Instituto Butantã), em São Paulo, também verificou que as crianças são as mais comumente atingidas.

A Figura 2 mostra que os membros superiores entram em contato mais facilmente com as lagartas, em escala de importância a saber: mão, braço e antebraço $\left(X^{2}=297,43 ; \mathrm{p}<0,0001\right)$. Isso reforça a observação de que os acidentes ocorrem normalmente quando as pessoas estão manipulando ou podando as plantas, e tocam as lagartas, sem avistá-las. 
Figura 2 - Áreas do corpo de contato com as lagartas, nos acidentes registrados em Ponta Grossa, PR, no período de 2007 a 2010.

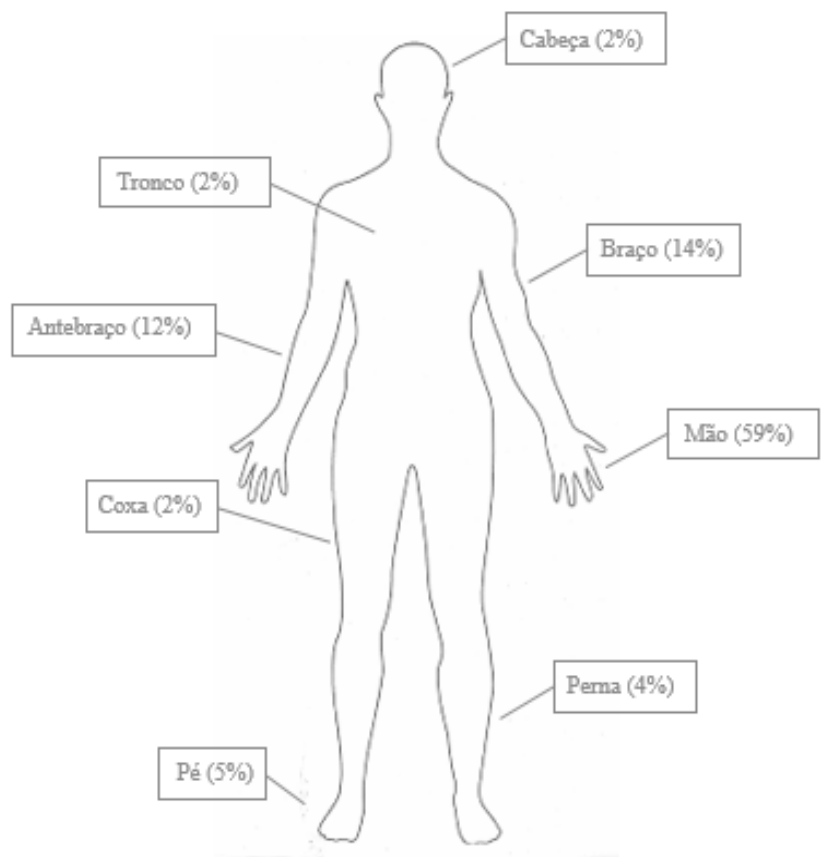

Fonte: Secretaria Municipal de Saúde - Vigilância Epidemiológica e Controle de Doenças SINAN NET - 2007 a 2010

Dados dos pacientes atendidos nos anos de 2007 a 2010 mostram que todos apresentaram manifestações locais, como dor, edema, equimose e necrose (Figura 3). Destas, dor (99\%) e edema (73\%) foram as mais frequentes, seguidas de outros sinais (43\%), que incluem eritema, bolhas e queimação. Além dessa variedade de quadros clínicos, $20 \%$ dos pacientes apresentaram ainda algumas manifestações sistêmicas, como mostra a Figura 4.

Figura 3 - Manifestações locais observadas entre os acidentados por lagartas urticantes em Ponta Grossa, no período de 2007 a 2010.

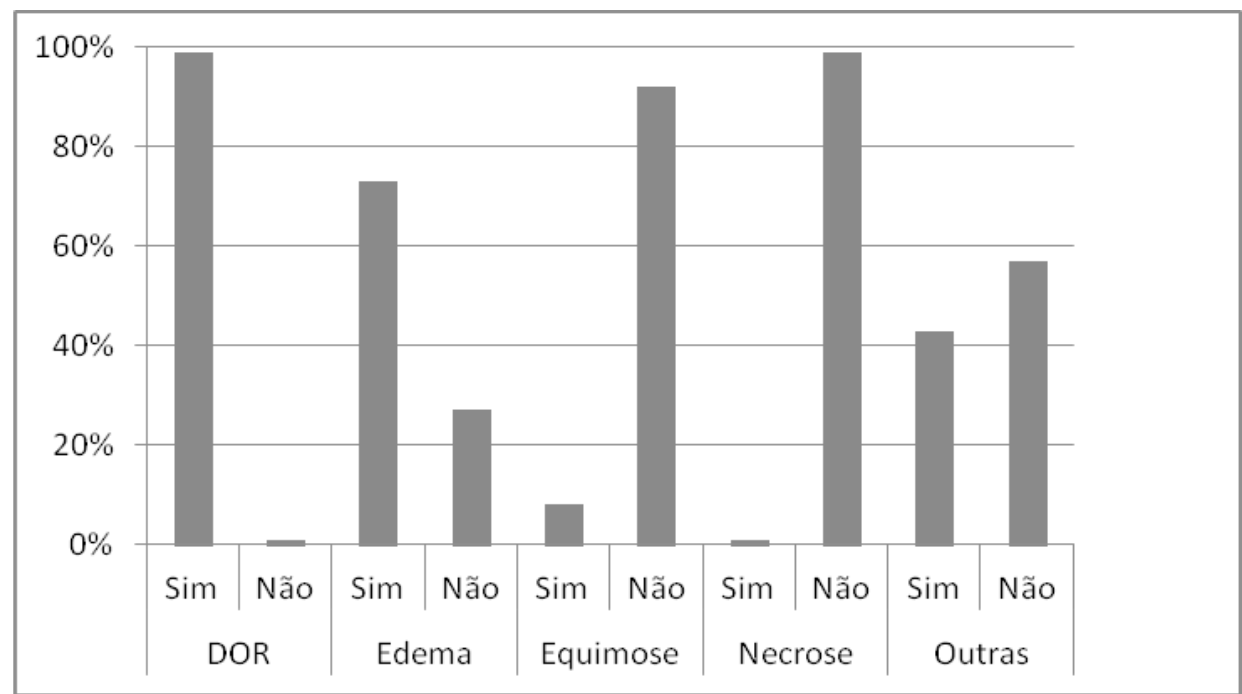

Fonte: Secretaria Municipal de Saúde - Vigilância Epidemiológica e Controle de Doenças - SINAN NET - 2007 a 2010. 
Figura 4 - Manifestações sistêmicas observadas entre os acidentados por lagartas urticantes em Ponta Grossa, no período de 2007 a 2010.

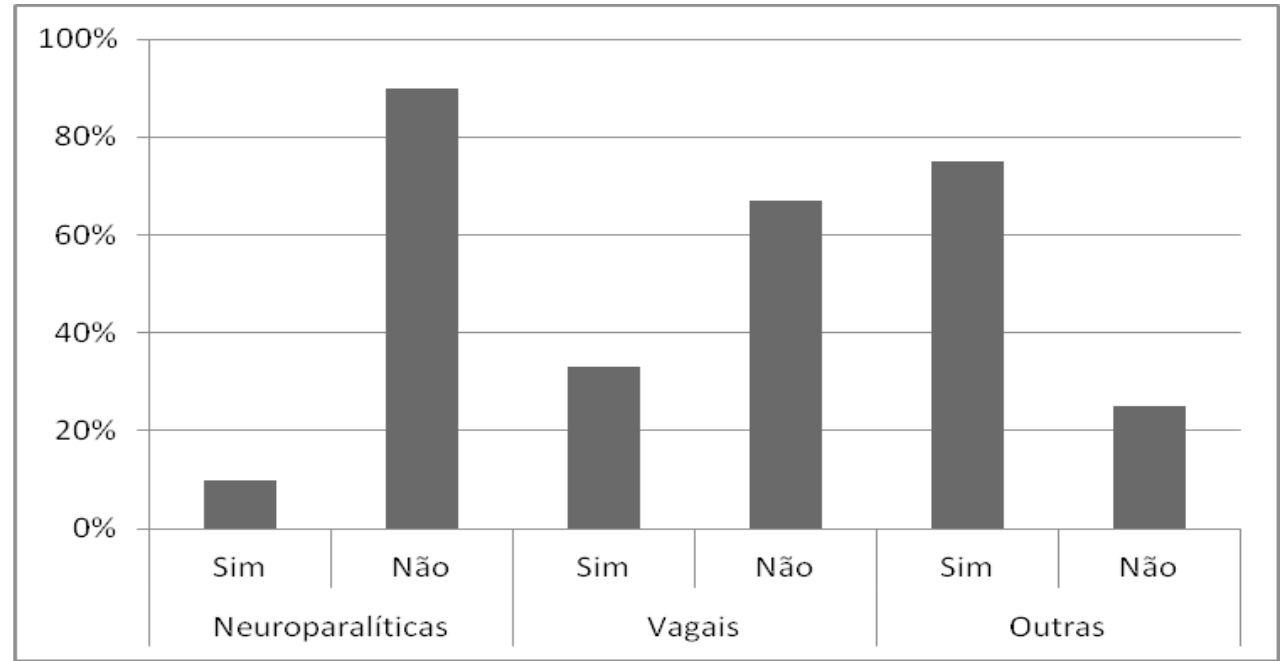

Fonte: Secretaria Municipal de Saúde - Vigilância Epidemiológica e Controle de Doenças - SINAN NET - 2007 a 2010.

Notou-se que as manifestações sistêmicas mais ocorrentes foram as vagais (33\%), que incluem vômitos e diarréias, e outras manifestações sistêmicas, como cefaleia e tontura, correspondendo a $75 \%$ dos casos. Isto ressalta o ponto levantado por Cardoso e Haddad Junior (2005), de que os acidentes causados por lepidópteros geram quadros clínicos diversos. Ainda deve ser levado em conta o fato de cada indivíduo responder de maneira diferente ao contato com os lepidópteros. No geral, os acidentes foram de curso agudo, de gravidade leve (96\%) a moderada (4\%) e evolução benigna, sem necessidade de soroterapia.
De modo geral, os acidentes por lagartas não são considerados graves, exceto aqueles decorrentes de contato por Lonomia. Em Ponta Grossa, apenas dois acidentes foram registrados como tendo sido causados por Lonomia até o momento, ambos no ano de 2009. Porém, a dificuldade na confirmação do agente causador do agravo é comum, tendo em vista que na maioria das vezes a lagarta não é capturada pelo acidentado, o que pode induzir ao erro na identificação das espécies de maior interesse médico por parte da equipe de vigilância de zoonoses (BRASIL, 2008).

Com relação à distribuição estacional, o maior número de acidentes foi notificado nos meses de fevereiro, março e abril (Figura 5).

Figura 5 - Sazonalidade dos acidentes por lagartas urticantes registrados em Ponta Grossa, PR, no período de 2007 a 2010.

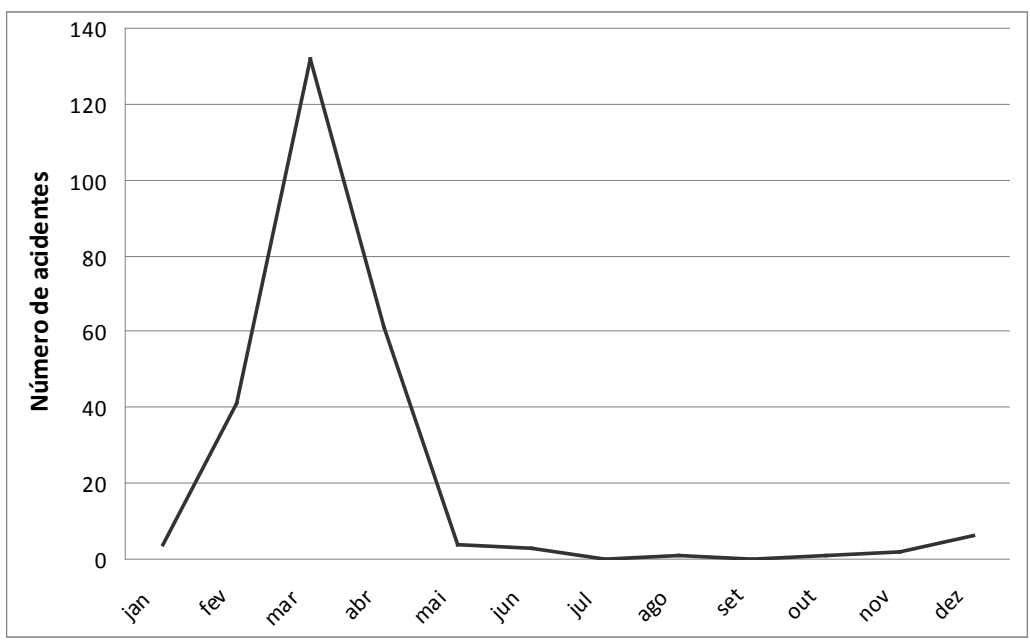

Fonte: Secretaria Municipal de Saúde - Vigilância Epidemiológica e Controle de Doenças - SINAN NET - 2007 a 2010. 
Observa-se uma sazonalidade na ocorrência desses acidentes, que corresponde aos meses quentes de verão. Mesmo fato foi observado por Garcia e Oliveira (2007) nos acidentes causados pela lagarta Lonomia obliqua Walker, que apresentam pico de ocorrência nos meses de fevereiro e março, estendendo-se durante toda primavera e verão, períodos que correspondem à fase de lagarta do inseto. A partir do outono, nota-se que há uma redução no número de acidentes que se tornam praticamente inexistentes nos meses de inverno. Esta sazonalidade está relacionada ao ciclo biológico das espécies e às atividades externas em jardins e quintais. Tais resultados corroboram também com as informações contidas no "Manual de diagnóstico e tratamento de acidentes por animais peçonhentos" (BRASIL, 2001) e os relatos de Campolina e Januário (2008) sobre o período de maior risco de erucismo, que se dá de fevereiro a abril.

\section{- Identificação das lagartas e suas plantas hospedeiras}

Foram coletados 22 exemplares sendo que 16 deles foram encaminhados ao laboratório pela população, totalizando 38 lagartas coletadas. Destas, duas não foram identificadas, pois uma foi classificada como lagarta não urticante e a outra se apresentava parasitada, o que impossibilitou seu reconhecimento. As lagartas identificadas pertencem às famílias Saturniidae, Megalopygidae, Limacodidae e Arctiidae, como mostrado na figura 6 . Todas consideradas como as principais famílias de lepidópteros causadoras de erucismo, segundo Moraes (2003) e três delas de acordo com o Ministério da Saúde (BRASIL, 2001).

Os Saturnídeos coletados pertencem à subfamília Hemileucinae, dos quais quatro são representantes do gênero Automeris. Todos os Megalopygidae foram identificados como do gênero Megalopyge e os Limacodidae como pertencentes ao gênero Sibine. Dentre os representantes de Arctiidae, dois pertencem à subfamília Arctiinae.

A Tabela 4 mostra a relação das plantas hospedeiras observadas para os lepidópteros coletados, dos quais $6 \%$ foram encontrados em locais como muros e calçadas e $94 \%$ em nove famílias de vegetais, com destaque para Rosaceae $(19,4 \%)$, Anacardiaceae $(16,1 \%)$ e Platanaceae (13\%).
Figura 6 - Famílias das lagartas urticantes capturadas em Ponta Grossa, PR, no período de outubro de 2010 a abril de 2011.

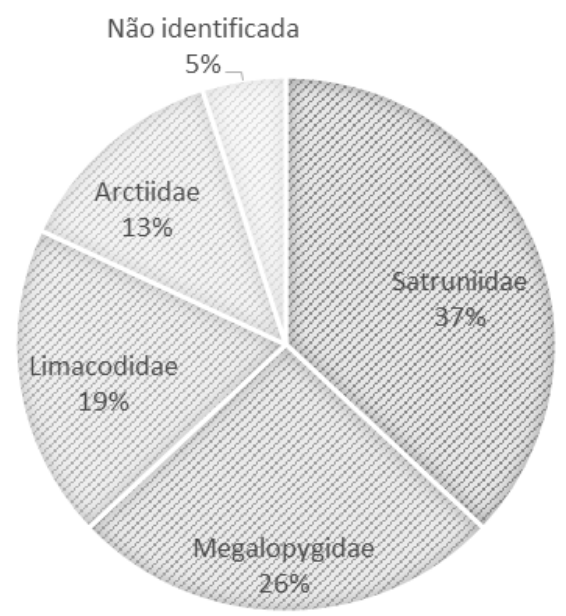

Tabela 4 - Relação das plantas hospedeiras das lagartas coletadas em Ponta Grossa, PR, no período de outubro de 2010 a abril de 2011.

\begin{tabular}{|c|c|c|c|}
\hline & \multicolumn{3}{|c|}{ Planta Hospedeira } \\
\hline Lagarta & Nome Vulgar & Nome Científico & Família \\
\hline Saturniidae & \begin{tabular}{|c} 
Roseira \\
Aroeira vermelha \\
Plátano \\
Limoeiro
\end{tabular} & $\begin{array}{c}\text { Rosa } \mathrm{sp} . \\
\text { Schinus terebinthifolius Raddi } \\
\text { Platanus } \mathrm{sp} . \\
\text { Citrus limon } \mathrm{L} .\end{array}$ & $\begin{array}{c}\text { Rosaceae } \\
\text { Anacardiaceae } \\
\text { Platanaceae } \\
\text { Rutaceae }\end{array}$ \\
\hline Megalopygidae & $\begin{array}{c}\text { Roseira } \\
\text { Aroeira vermelha } \\
\text { Goiabeira } \\
\text { Dedaleiro }\end{array}$ & $\begin{array}{c}\text { Rosa } \mathrm{sp} . \\
\text { Schinus terebinthifolius } \text { Raddi } \\
\text { Psidium guajava } \mathrm{L} \text {. } \\
\text { Lafoensia pacari A.St.-Hil. } \\
\text { Tibouchina } \mathrm{sp} . \\
\text { Liquidambar } \mathrm{sp} .\end{array}$ & $\begin{array}{c}\text { Rosaceae } \\
\text { Anacardiaceae } \\
\text { Myrtaceae } \\
\text { Lythraceae } \\
\text { Melastomalaceae } \\
\text { Altingiaceae }\end{array}$ \\
\hline Arctiidae & $\begin{array}{l}\text { Roseira } \\
\text { Aleluia }\end{array}$ & $\begin{array}{l}\text { Rosa sp. } \\
\text { Parte superior do formulário } \\
\text { Senna multijuga } \text { Rich }\end{array}$ & $\begin{array}{l}\text { Rosaceae } \\
\text { Fabaceae }\end{array}$ \\
\hline Limacodidae & $\begin{array}{c}\text { Roseira } \\
\text { Plátano } \\
\text { Goiabeira }\end{array}$ & $\begin{array}{c}\text { Rosa } \mathrm{sp} . \\
\text { Platanus } \mathrm{sp} . \\
\text { Psidium guajava } \mathrm{L} .\end{array}$ & $\begin{array}{c}\text { Rosaceae } \\
\text { Platanaceae } \\
\text { Myrtaceae }\end{array}$ \\
\hline
\end{tabular}


Em um estudo com a família Limacodidae, Specht; Corseuil e Formentini (2005a, b) identificaram-se 43 espécies de plantas hospedeiras, com destaque para: Rosaceae, Myrtaceae, Rutaceae, Anacardiaceae e Arecaceae, as duas primeiras também observadas em Ponta Grossa (PR).

Já no Uruguai, Biezanko; Ruffinelli e Link (1974) identificaram 16 famílias de plantas hospedeiras para Megalopyge (Megalopygidae), dentre elas Rosaceae, a qual também foi observada em nosso trabalho para este mesmo lepidóptero. No mesmo trabalho, foram reconhecidas como sendo as plantas hospedeiras mais ocorrentes para Arctiidae as famílias Asteraceae, Fabaceae, Solanaceae e Rosaceae, corroborando, assim, com nossos resultados.

Por outro lado, os resultados divergem dos observados por Monteiro et al (2007). Em seu trabalho, ele observa um maior número de espécies de lepidópteros em Manilkara subsericea, pertencente à família Sapotaceae, a qual não foi encontrada nessa pesquisa.

Desta maneira, destaca-se o cuidado que devemos ter ao manusear plantas em quintais e parques, para assim evitarmos possíveis acidentes, principalmente com plantas da família Rosaceae, que inclui plantas muito comuns nas casas como as roseiras, e Platanaceae, como o plátano.

Nota-se, no entanto, certa dificuldade em encontrar registros de plantas hospedeiras das lagartas de importância médica, pois os estudos, em geral, estão relacionados com pragas agrícolas.

\section{CONCLUSÃO}

No período de 2007 a 2010, ocorreram 255 registros de acidentes por lagartas urticantes em Ponta Grossa, sendo que o período que ao verão apresenta maior perigo para ocorrência de acidentes. Na cidade, foram encontradas as quatro famílias de importância médica: Arctiidae, Limacodidae, Megalopygidae e Saturniidae. Os dados analisados mostram que os membros superiores são as partes do corpo mais atingidas, com destaque para as mãos, representando 59\% dos registros, sendo que a faixa etária mais propensa aos acidentes a de indivíduos entre 7 a 29 anos. Em relação às plantas hospedeiras, as lagartas foram encontradas em nove famílias diferentes, das quais devemos destacar as famílias Rosaceae e Platanaceae. Estes resultados permitiram caracterizar alguns aspectos do erucismo na cidade de Ponta Grossa, ao identificar as principais lagartas urticantes e definir os bairros com maior risco de acidentes, podendo, dessa forma, contribuir com informações relevantes sobre a epidemiologia e a biologia das espécies. Ressalta-se, também, a importância da ampliação dos inquéritos entomológicos que possibilitem mapear de forma mais precisa as áreas de distribuição destes lepidópteros, e também a necessidade de se abordar o tema erucismo junto à população, com enfoque nos cuidados e prevenção destes acidentes.

\section{REFERÊNCIAS}

BIEZANKO, C. M.; RUFFINELLI, A.; LINK, D. Plantas y otras substancias alimentícias delas orugas de los lepidópteros uruguayos. Rev. Centro Ciências Rurais, v.4, n.2, p. 107-148, 1974.

BRASIL. Ministério da Saúde. Fundação Nacional de Saúde. Manual de diagnóstico e tratamento de acidentes por animais peçonhentos. 2 ed. Brasília, 2001.

Secretaria de Vigilância em

Saúde. Boletim eletrônico epidemiológico: situação epidemiológica das zoonoses de interesse à saúde pública. Brasília, 2009. Disponível em: <http://www.scalibor.com. br/downloads/Boletim_zoonoses_2008.pdf $>$. Acesso em: 17 out. 2011.

Acidentes por animais $\overline{\text { peçonhentos - lagartas: }}$ situação epidemiológica. Disponível em: < http://portal.saude.gov.br/portal/saude/ profissional/area.cfm?id_area $=1538>$. Acesso em 17 out 2011.

CAMPOLINA, D.; JANUÁRIO, M. C. Acidentes por animais peçonhentos In: Marco Tulio Baccarini. (Org.). Erazo Manual de Urgência em Pronto-Socorro. 1ed.Rio de Janeiro: Guanabara Koogan, 2006, v. 1, p. 869-888.

CANTER, H.M. et al. Taturanas. Série didática 6. São Paulo, SP s/d. Disponível em: <http://www. conscienciaprevencionista.com.br/upload/arquivo download/1962/PREVEN\%C3\%87\%C3\%83O\%20 DE\%20ACIDENTES\%20COM\%20ANIMAIS\%20-\%20 TATURANAS.pdf $>$. Acesso em: 5 abr. 2011.

CARDOSO, A. E. C.; HADDAD JUNIOR, V. Acidentes por Lepidópteros (larvas e adultos de mariposas): estudo dos aspectos epidemiológicos, clínicos e terapêuticos. An. Bras. Dermatol. v.80, n.6, p. 571-578, 2005. Disponível em: <http://www.scielo.br/pdf/abd/v80n6/v80n06a02.pdf > . Acesso em: 16 mar. 2011.

CONCCEPAR, VI. 2015. Campo Mourão. Anais...Campo Mourão: Faculdade Integrada de Campo Mourão, 2015. Disponível em: <http://conccepar2015.grupointegrado.br/ resumo/fenologia-da-quaresmeira-tibouchina-granulosa- 
cultivada-nas-ruas-de-campo-mourao-pr/616>. Acesso em 24 ago. 2016.

COSTA, C.; IDE, S.; SIMONKA, C. E. Insetos imaturos. Metamorfose e identificação. Ribeirão Preto: Holos, 2006. 249 p.

COSTA, R. M. Acidentes por lagartas venenosas. In: BARRAVIERA B. Venenos animais: uma visão integrada. Rio de Janeiro: Publicações Científicas, p. 327-338, 1994.

GARCIA, C. M.; OLIVEIRA, I. M. Ocorrência de acidentes provocados por Lonomia obliqua Walker, no estado do Paraná, no perído de 1989 a 2001. Revista Brasileira de Medicina Tropical, v. 40, n. 2, mar.-abr. 2007

GOUVEIA, A. I. C. B. Bioprospecção de toxinas presentes na hemolinfa e extrato de cerdas da lagarta Lonomia obliqua. Curitiba, 2004. Dissertação (Mestrado em Biologia Celular e Molecular) - Universidade Federal do Paraná.

GULLAN, P. J.; CRANSTON, P. S. Os insetos: um resumo de entomologia. 3. ed. São Paulo: Roca Ltda., 2007. 440 p.

MARTINS, C. B. G.; ANDRADE, S. M.; PAIVA, P. A. B. Envenenamentos acidentais entre menores de 15 anos em município da Região Sul do Brasil. Cadernos de Saúde Pública, Rio de Janeiro, v. 22, n. 2, fev./2006.

MAGGI, S.; FAULHABER, G. A. M. Lonomia obliqua Walker (Lepidoptera: Saturniidae): hemostasis implications. Revista da Associação Medédica Brasileira, São Paulo, v. 61, n. 3, mai./jun. 2015.

MONTEIRO, R. F. et al. Composição, abundância e notas sobre a ecologia de espécies de larvas de lepidópteros associadas a cinco espécies de plantas hospedeiras no Parque Nacional da Restinga de Jurubatiba, RJ. Revista Brasileira de Entomologia, Rio de Janeiro, v 51, n. 4, p.476-483, dez. 2007.

MORAES, R. H. P. Lepidópteros de importânicia médica. In: CARDOSO, J. L. C.; FRANÇA, F. O. S.; WEN, F. H.; MÁLAQUE, C. M. S.; VIDAL, H. J. Animais peçonhentos no Brasil: biologia, clínica e terapêutica dos acidentes. São Paulo: Sarvier, 2003. cap. 21. p. 211-219.

RUBIO, G. B. G. Vigilância Epidemologica de Distribuição da Lagarta Lonomia obliqua, Walker, 1855, no Estado do Paraná: Brasil. Cad. de Saúde Pública, Rio de Janeiro; v.17, n.4, p. 1036, 2001.

SPECHT, A.; CORSEUIL, E.; FORMENTINI, A. C. Lepidópteros de importância médica ocorrentes nos Rio Grande do Sul. II. Aididae e Limacodidae. Biociências, Porto Alegre, v.13, n.1, p. 89-94, jun. 2005a.

Lepidópteros de importância médica ocorrentes nos Rio Grande do Sul. III. Saturniidae Hemileucinae. Biociências, Porto Alegre, v.13, n.2, p. 149162, dez. 2005 b. 